\title{
Examination of Tumor Regression Grading Systems in Breast Cancer Patients Who Received Neoadjuvant Therapy
}

\author{
Anita Sejben ${ }^{1}$ (1) $\cdot$ Renáta Kószó ${ }^{2} \cdot$ Zsuzsanna Kahán $^{2} \cdot$ Gábor Cserni $^{1,3} \cdot$ Tamás Zombori $^{1}$
}

Received: 16 April 2020 / Accepted: 29 June 2020 / Published online: 20 July 2020

(C) The Author(s) 2020

\begin{abstract}
Neoadjuvant therapy is a common form of treatment in locally advanced breast cancer (LABC) patients. Besides some guidelines for grading regression, a standardized general scheme is not yet available. The aim of our study was to compare the prognostic impact of different regression grading systems, namely the TR/NR, Chevallier, Sataloff, Denkert-Sinn, Miller-Payne, NSABPB18, Residual Disease in Breast and Nodes and Residual Cancer Burden (RCB) on disease-free (DFS) and overall survival (OS). Data of 746 breast cancer patients treated in neoadjuvant setting between 1999 and 2019 have been included. The different regression grades and follow-up data were collected from medical charts. Statistical analysis included the Kaplan-Meier method, log-rank test and multivariate Cox regression. The average patient age was 55 years. The DFS and OS estimates of patients with complete pathological regression and residual in situ carcinoma have been significantly more favorable than those having partial regression or no signs of regression (pDFS $<0.001$, pOS $<0.001$ ). Significant differences were found between DFS estimates of classes with partial regression and without regression defined by RCB. Concerning DFS estimates, the RCB classification $(p=$ $0.019)$, while regarding OS data the $\mathrm{y}$-stage $(p=0.011)$ and the nodal status ( $\mathrm{ypN} ; p=0.045$ ) were significant prognosticators by multivariate Cox regression. Regression grading systems help the evaluation of regression in LABC patients treated with neoadjuvant therapy. Of the several grading systems compared, the RCB classification makes the best distinction between the outcomes of the different classes, therefore we recommend the inclusion of RCB into the histopathological findings.
\end{abstract}

Keywords Breast cancer $\cdot$ Neoadjuvant therapy $\cdot$ Regression pattern $\cdot$ Grading systems $\cdot$ Residual cancer burden

\section{Introduction}

Treatment of locally advanced breast cancer (LABC) patients has been one of the great challenges of breast oncology for a long time. Patients with such advanced disease benefit from treatment devised by a multidisciplinary team of specialists: oncologists, surgeons, pathologists and radiologists [1].

Electronic supplementary material The online version of this article (https://doi.org/10.1007/s12253-020-00867-3) contains supplementary material, which is available to authorized users.

Anita Sejben

sejben.anita@gmail.com

1 Department of Pathology, Faculty of Medicine, University of Szeged, Állomás u. 1., Szeged 6725, Hungary

2 Department of Oncotherapy, University of Szeged, Szeged, Hungary

3 Department of Pathology, Bács-Kiskun County Teaching Hospital, Kecskemét, Hungary
Neoadjuvant therapy (NAT) has changed the management of LABC, since it can achieve reduction or even complete regression of the primary tumor and its metastases [2, 3]. This downstaging can allow some patients who would have had mastectomy as surgical treatment to be treated with breast conservation [4]. While receiving NAT, patients have to be under constant oncological and radiological follow-up [5]. The effectiveness of NAT completed with surgical and if needed postoperative endocrine treatment seems to be equivalent with adjuvant therapy on the basis of disease-free (DFS) and overall survivals (OS) [6, 7]. Pathological complete regression occurs more frequently in triple negative or HER-2 positive cancers than in ER positive ones [8, 9].

The work-up of surgical specimen after NAT requires the undivided attention of the pathologist. The identification of the primary tumor bed can be challenging because of its resemblance to fibrotic breast tissue. Insertion of metal clips into the tumor and/or specimen mammography can simplify the identification process. Specimen sampling requires adequate radio-pathological correlation $[10,11]$. The evaluation of 
tumor regression after NAT has to be established with full consideration given to radiology, gross morphology and microscopy.

The characterization of regression differs from country to country due to lack of international consensus on definitions. Pathological complete regression (pCR) implies no residual tumor in the surgical specimen, but the meaning is interpreted variously. In some European countries, pCR generally means the absence of in situ or invasive tumor tissue in the specimen. A significant difference in DFS between ypT0ypNOM0 and ypTisypN0M0 was demonstrated by the German and Austrian Breast Groups [12]. The United States Department of Health and Human Services Food and Drug Administration Center for Drug Evaluation and Research and the American Joint Committee on Cancer define pCR as the absence of residual invasive cancer in the surgical specimen $[13,14]$.

The histology of post-NAT tumors represents a spectrum from pCR to tumor growth and progression (Fig. 1) [15]. Regression can be reflected by the changes in tumor size, the cellularity of the tumor bed, the presence of lymph node metastases and of ductal carcinoma in situ (DCIS). Since all of these factors may affect prognosis, it is essential that all are represented in the histopathological findings [16]. One of the
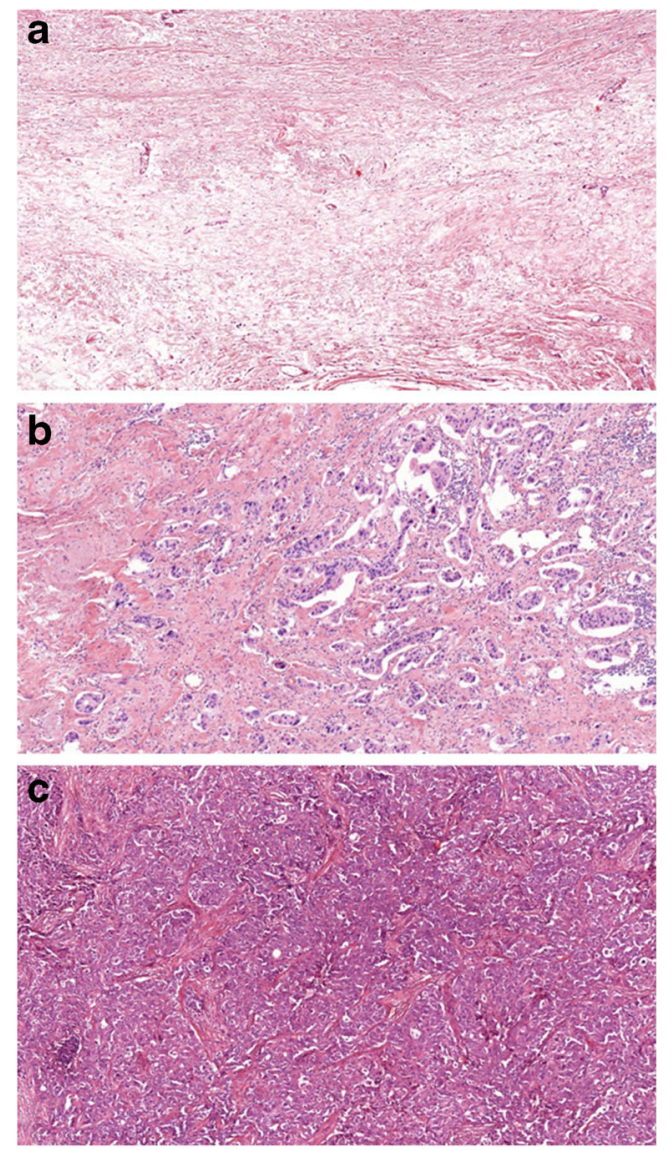

Fig. 1 Spectrum of tumor regression: Complete pathological regression (a), partial regression (b) and lack of regression (c) (HE, A: 4x, B and C: 10x) most essential prognostic factors in breast cancer after NAT continues to be the size of the invasive cancer. In case of unifocal tumors the largest tumor dimension will produce the ypT category, while in cases of multifocal ones the largest diameter of cancer cell containing tissue will be the defining factor.

The evaluation of regression remains a complicated and versatile task especially due to worldwide application of numerous grading systems. The firstly described National Surgical Adjuvant Breast and Bowel Project (NSABP) B18 classifies all NAT cases into two groups. The first group contains pCR cases (including ypT0 and ypTis) whereas the second group refers to all residual invasive tumor cases [17]. Further regression grading systems, namely Chevallier, Sataloff, Miller-Payne, Denkert-Sinn, Residual Cancer Burden (RCB), TR/NR (suggested system in the European guidelines for measuring tumor regression and nodal regression) and Residual disease in breast and nodes (RDBN) define the presence or absence of complete pathological regression with one or more categories for tumors with some regression [18-24]. The TR/NR, Sataloff and RCB systems take residual tumor burden into account, the Chevallier grade considers the presence of some regression, while the Denkert-Sinn grade includes tumor size, and the Miller-Payne system integrates change of cellularity between the biopsy and the resection specimen. The Sataloff, TR/NR and RCB grading systems include lymph node status as well $[22,19,11]$. The RDBN score can be calculated by the following equation RDBN = $0,2 x$ tumor size $(\mathrm{mm})+$ Nottingham histologic grade $(1-3)+$ lymph node involvement $(0-3)$. According to the RDBN score a good $(\leqslant 3.4)$, a moderate $(3.4<$ and $\leqslant 5.4)$, and poor ( $>5.4)$ prognostic group were identified [24]. The quantification of residual tumor can be performed by using the RCB calculation. The algorithm was developed by Symmans and coworkers and takes notice of the two largest diameters of the residual tumor, the presence and proportion of DCIS and the number of metastatic lymph nodes with the size of the largest nodal metastasis [22]. The evaluation of RCB is supported by the online available RCB calculator (http://www3. mdanderson.org $/ \mathrm{app} / \mathrm{medcalc} / \mathrm{index} . \mathrm{cfm}$ ? pagename= jsconvert3).

Table 1 represents tumor regression grading systems evaluated in our study and defines the differences among them. Although these grading systems are validated, none of them are accepted internationally. The Hungarian protocol in regression grading was recommended by the 3rd Hungarian Consensus Conference on Breast Cancer in 2016 and is practically identical with the recommendation of the European Working Group for Breast Screening Pathology (EWGBSP) $[11,23]$. In Germany, the Denkert-Sinn grade is utilized, while in the USA and many other countries the RCB becomes increasingly adopted. 


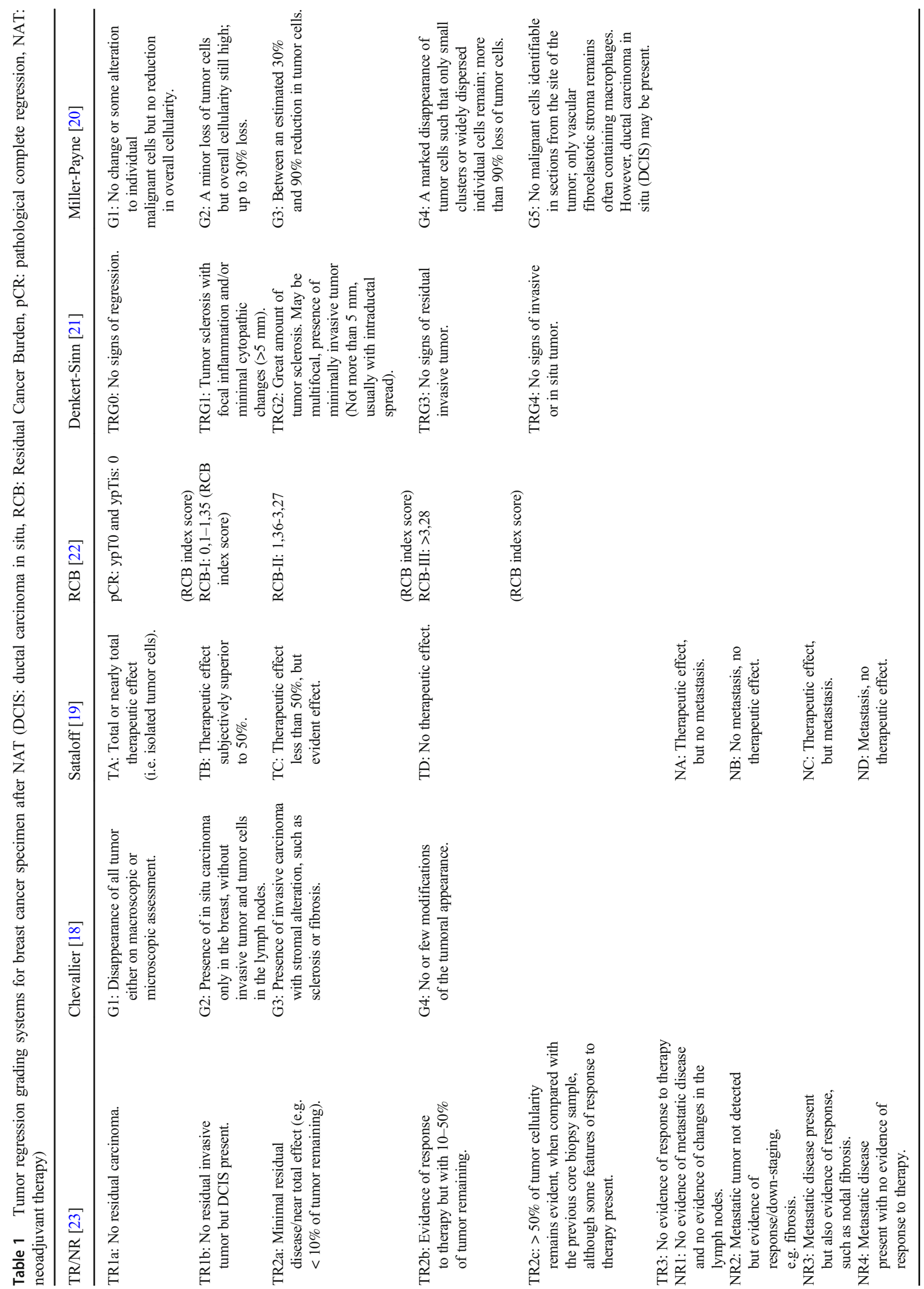


The aim of our study was to evaluate the prognostic impact (on disease-free and overall survival) of the different tumor regression grading systems in breast cancer patients treated with NAT. We also aimed to identify which of the grading systems could best reflect prognosis.

\section{Materials and Methods}

NAT receiving, consecutive patients operated on for histologically verified invasive breast carcinoma at the Department of Surgery, University of Szeged or Bács-Kiskun County Teaching Hospital, Kecskemét between 1999 and 2019 were included in our retrospective study. Follow up data were collected from medical charts.

The following clinical and pathological variables were obtained for analysis: age, gender, localization, type of neoadjuvant and surgical treatments, DFS and OS; histological type and grade of cancer in previous core biopsy and surgical specimen, completeness of the resection, vascular invasion, size possibly in 2 dimensions, ypT, ypN, ystage, tumor cell density, tumor cellularity in biopsy and resection specimens, presence and proportion of DCIS, presence of metastasis and/or regression in lymph nodes, size of metastatic deposits and receptor status (estrogen receptor - ER, progesterone receptor - PR, and human epidermal growth factor receptor-2 HER2). Tumor cell density was defined as the proportion of viable tumor cells in the complete tumor bed, not including necrosis or DCIS.

Regression grades (NSABP-B18, TR/NR, Chevallier, Sataloff, Denkert-Sinn, Miller-Payne, and RCB) and morphological variables were correlated with DFS and OS data using Kaplan-Meier estimates. Patients were followed from the date of initiation of NAT until the time of recurrence or tumorrelated death. Patients alive without recurrence and patients dying from other causes were censored at the time of the last follow-up and death, respectively. The log-rank test was used for pairwise comparisons. All statistical tests were two-sided and $p<0.05$ values were considered statistically significant. The parameters found significant in the univariable models were entered in multivariable Cox proportional hazard model to identify factors of independent prognostic significance. Statistical models were fitted using SPSS Statistics V.22.0 software (IBM, SSPS 22.0, Armonk, NY USA).

This retrospective study was approved by the regional ethical committee of the Albert Szent-Györgyi Clinical Centre of the University of Szeged.

\section{Results}

Data of 746 patients who underwent NAT and surgical resection were collected. The median patient age was 55 years (range: 26-91) and 2 of them were males. Table 2 summarizes the oncological and surgical treatments of all patients in the examined population. The majority of patients received primary chemotherapies, whereas $16.4 \%$ got primary endocrine therapy. Regarding primary systemic chemotherapy, the majority of patients were given third generation (taxane containing) regimens. $11.2 \%$ of the patients had been given second generation (anthracycline based) chemotherapeutics. Patients who received a combination of platinum compounds with cyclophospamide fell into the "others" category. Anti-Her2 treatment was essentially given in combination with chemotherapy. Concerning primary endocrine therapy, the most frequent agents used were aromatase inhibitors and the average hormonal therapy treatment period was 1 year. The majority of patients underwent mastectomy. Re-excisions were rarely performed and were done because of positive or close resection margins. Regional lymph nodes were examined in almost all cases, most commonly by means of axillary lymph node dissection.

As Table 3 demonstrates, with histological examination, $87.8 \%$ of patients had invasive carcinoma „No Special Type" in surgical specimens. Invasive tubular, mucinous, medullary and metaplastic breast cancers were categorized into the others category. The presence of residual DCIS was described in 212 cases. One fifth of the patients achieved pCR. The most frequent pathological tumor category was ypT2

Table 2 Types of NAT and surgical treatment in the examined population (LHRH: Luteinizing hormone-releasing hormone, HER2: Human epidermal growth factor receptor 2, SNB: Sentinel node biopsy, ALND: Axillary lymph node dissection)

\begin{tabular}{lll} 
Neoadjuvant therapy & & \\
\hline Primary hormonal therapy $(n=123=100 \%)$ & $\mathrm{n}$ & $\%$ \\
Tamoxifen & 4 & 3.25 \\
Aromatase inhibitor & 102 & 82.93 \\
Tamoxifen and LHRH-analogue & 3 & 2.44 \\
Aromatase inhibitor and LHRH-analogue & 14 & 11.38 \\
Primary chemo- and target therapy $(n=623=100 \%)$ & $\mathrm{n}$ & $\%$ \\
Second generation chemotherapy & 70 & 11.24 \\
Third generation chemotherapy & 550 & 88.28 \\
Others & 3 & 0.48 \\
Anti-HER2 (in combination therapy) & 91 & 14.60 \\
Number of cycles should go under Primary chemo-and & 5.60 & 6.00 \\
target therapy) & & \\
Surgical treatment $(n=746=100 \%)$ & $\mathrm{n}$ & $\%$ \\
Breast conserving excision & 249 & 33.38 \\
Mastectomy & 497 & 66.62 \\
Re-excision & 17 & 2.28 \\
SNB & 72 & 9,65 \\
ALND & 593 & 79,49 \\
SNB + ALND & 60 & 8.04 \\
\hline
\end{tabular}


Table 3 Morphological features of breast cancer in the examined population (NST: Invasive carcinoma „No Special Type”, ILC: Invasive lobular carcinoma, DCIS: Ductal carcinoma in situ, R: Resection, V: (Lympho) vascular invasion, Pn: Perineural invasion, HR: Hormone (estrogen and/or progesterone) receptor, HER2: Human epidermal growth factor receptor 2; ypT and ypN categories are defined by AJCC. Not all evaluated features were available for all cases, hence the differences in the sums of some rows

\begin{tabular}{|c|c|c|}
\hline Histological subtype (core) & $n$ & $\%$ \\
\hline NST & 655 & 87.80 \\
\hline ILC & 55 & 7.37 \\
\hline others & 36 & 4.83 \\
\hline grade & $n$ & $\%$ \\
\hline 1 & 35 & 4.69 \\
\hline 2 & 246 & 32.98 \\
\hline 3 & 420 & 56.30 \\
\hline No data & 45 & 6.03 \\
\hline DCIS (present) & 212 & 28.41 \\
\hline $\mathrm{R}(\mathrm{R} 1 / \mathrm{R} 0)$ & $130 / 616$ & 17.42 \\
\hline V (V1/V0) & $151 / 560$ & 21.23 \\
\hline $\operatorname{Pn}(\operatorname{Pn} 1 / \operatorname{Pn} 0)$ & $10 / 324$ & 2.99 \\
\hline Hormonal state & $n$ & $\%$ \\
\hline HR +, HER-2 - & 439 & 58.85 \\
\hline HER-2 +, HR +/- & 126 & 16.89 \\
\hline Triple negative & 181 & 24.26 \\
\hline ypT & $n$ & $\%$ \\
\hline урТ0 & 106 & 14.21 \\
\hline ypTis & 28 & 3.75 \\
\hline ypT1a & 48 & 6.43 \\
\hline ypT1b & 25 & 3.35 \\
\hline ypT1c & 110 & 14.75 \\
\hline урТ2 & 151 & 20.24 \\
\hline урT3 & 55 & 7.37 \\
\hline урT4 & 29 & 3.90 \\
\hline No data & 194 & 26.00 \\
\hline ypN & $n$ & $\%$ \\
\hline ypN0 & 290 & 38.87 \\
\hline ypN1 & 227 & 30.43 \\
\hline ypN2 & 127 & 17.02 \\
\hline ypN3 & 61 & 8.18 \\
\hline No data & 41 & 5.50 \\
\hline ystage & $n$ & $\%$ \\
\hline 0 & 9 & 1.21 \\
\hline I & 75 & 10.05 \\
\hline II & 209 & 28.02 \\
\hline III & 207 & 27.75 \\
\hline IV & 6 & 0.80 \\
\hline No data & 240 & 32.17 \\
\hline
\end{tabular}

(20.2\%), while $38.9 \%$ of the patients fell in with ypN0 category. Most cases expressed ER and PR, while HER-2 positivity was observed in 126 cases (17\%). Median patient follow up was 53.8 months (range: 4-238 months; average: 65.1 months). Relapse occured in $34.85 \%$ of cases during the follow-up period and tumor specific death was observed in $122(16,3 \%)$ cases.

According to the original histopathology reports, the numbers of patients evaluated with the different regression grading systems are as follows: NSABP-18 grade: 746, Chevalliergrade: 717 , Sataloff (T) grade: 494, Miller-Payne grade: 386, TR grade: 392 , Denkert-Sinn grade: 348 , RDBN grade: 405 and RCB: 212. Figure 2 and Supplementary Fig. 1-8 show the disease-free survival and overall survival estimates of the different grading systems, respectively. The DFS and OS estimates of complete pathological regression (ypT0) and residual in situ carcinoma (ypTis) together were significantly different from the survivals of tumors without regression and moderate regression categories in all grading systems $(p<0.001)$. There was no significant DFS and OS difference observed between the ypT0 and ypTis categories. Survival values associated with different partial or no response categories showed no significant differences between each other, with the exceptions of DFS for the RCB-I vs III and II vs III categories.

As all regression grading systems showed a significant effect on survival in the univariable models, they were all entered in the multivariable Cox-regression analysis. According to our results the RCB $(p=0.019)$ proved to be an independent prognostic marker for DFS, whereas the ystage $(p=0.011)$ and lymph node status $(p=0.045)$ showed similar results for OS.

\section{Discussion}

Due to the increasing use of NAT in patients having locally advanced breast cancer, more and more articles about its effectiveness have been published [8]. Although imaging techniques serve as great options to monitor regression after NAT, histopathological review remains the gold standard in the evaluation procedure [25]. Although several national guidelines aiming at the standardization of specimen cut up and reporting have been introduced, for example in Australia, Belgium, Germany, the UK, Netherlands, the USA and Hungary, there is no international agreement in the interpretation of tumor regression, in the definition of $\mathrm{pCR}$, and in the measurement of tumor size in cases where fibrosis develops as a result of NAT or multifocality is present [11,26-31].

Several regression grading systems have been introduced which are based on prognostic markers such as tumor size (in one or more dimensions), change in cellularity, presence of DCIS, presence of regression or metastasis in lymph nodes and the size of lymph node metastasis [17-23]. The definition of pCR and the complete lack of regression -as the extreme ends of the regression spectrum- are common features of these systems which also define one or more subgroups for partial regression 


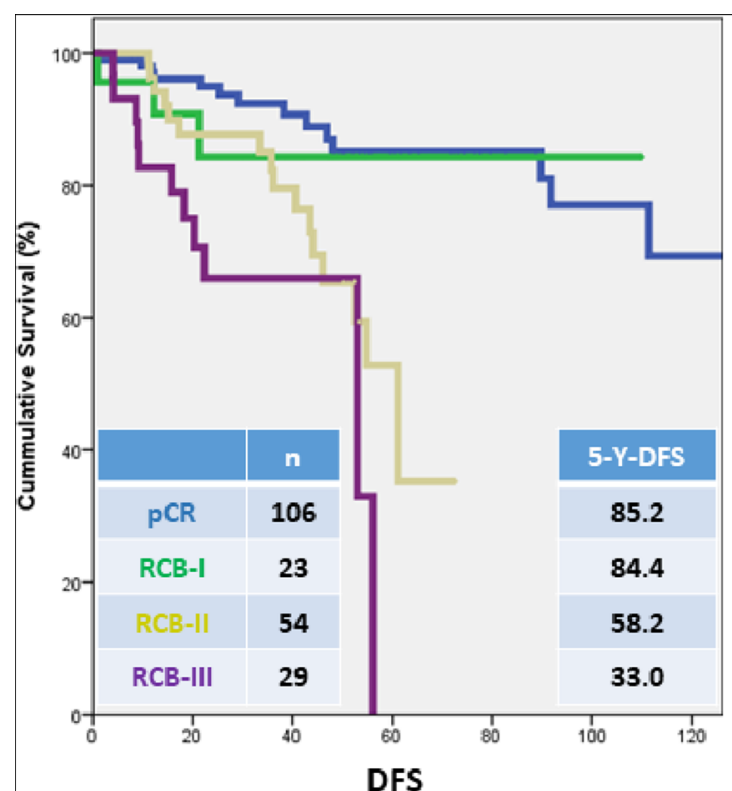

Fig. 2 Kaplan-Meier evaluation of the RCB grading system for DFS and OS. Significant differences were found between DFS estimates of pCR vs. RCB-II $(p<0.001)$, pCR vs. RCB-III ( $p<0.001)$, RCB-I vs. RCB-III $(p=0.035)$, RCB-II vs. RCB-III $(p=0.05)$. Regarding OS, significant

categories. Despite of the relative abundance of regression grading systems, there is a lack of international consensus on their application. All grading systems attempt to quantify the degree of regression or the amount of residual tumor, and there is agreement that a quantitative characterization of tumor regression is necessary for the evaluation of the effectiveness of NAT, and may have further role in therapeutic decisions (e.g. alternative treatments if no regression is present).

Although the presence of residual DCIS has been reported to convey a worse prognosis than complete absence of in situ and invasive carcinoma, there was no significant difference between OS and DFS estimates of ypTOypN0 and ypTisypN0. Our results are therefore supporting the more permissive definition of $\mathrm{pCR}$ (including ypTis) defined by the United States' FDA and endorsed by the AJCC $[13,14]$ and the European Guidelines [23]. Our findings regarding the prognostic impact of pCR are in keeping with those of others, since patients with $\mathrm{pCR}$ had a favorable prognosis (both in DFS and OS) compared to patients having partial regression. Concerning the subcategories of partial regression, we observed significant differences only between DFS estimates of certain RCB classes, namely between RCB-I vs. RCB-III and RCB-II vs. RCB-III classes. No other regression classification system showed subgroups of partial response with significant differences between each other.

The RCB system was developed by Symmans and coworkers in 2007. In their study, the prognostic role of morphological variables was evaluated by Cox-regression, and from variables found statistically significant, a complex equation was produced to determine the RCB index score. The RCB index score was

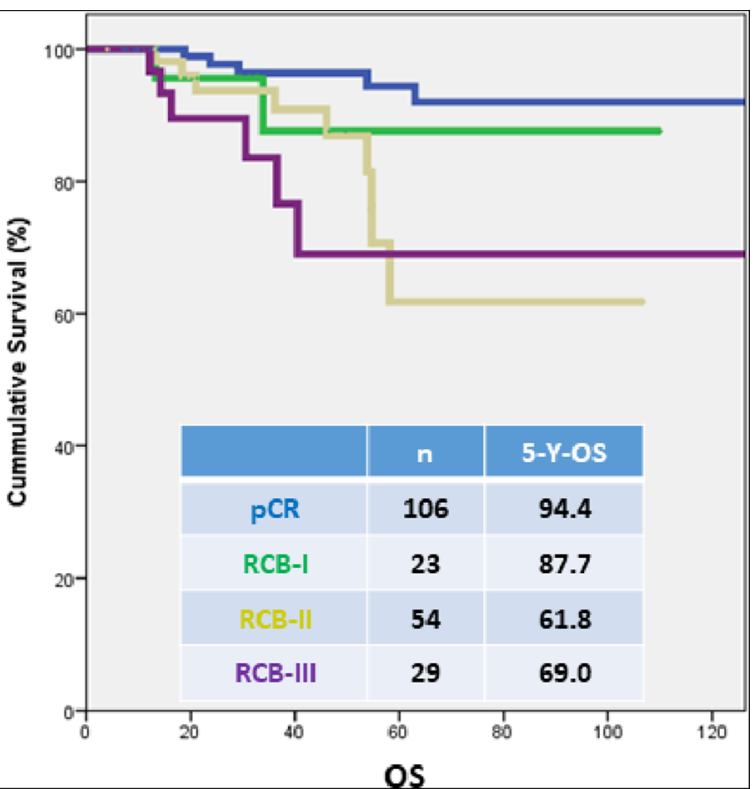

differences were observed between estimates of $\mathrm{pCR}$ vs. RCB-II ( $p=$ $0.005)$ and pCR vs. RCB-III ( $<<0.001)$, respectively (RCB: Residual Cancer Burden, DFS: disease-free survival, OS: overall survival, pCR: pathological complete regression)

correlated with survival data and cut-off scores were assigned to identify the RCB classes. In concordance with the original results by Symmans et al., there were no significant differences in DFS and OS estimates between RCB-0 (pCR) and RCB-I (nearly $\mathrm{pCR}$ ) classes. Furthermore, the multivariable Cox regression models for DFS suggest that the RCB system is the only significant prognosticator among regression grades $(p=0.019)$ [22].

In a subsequent publication, Symmans and co-authors have demonstrated that the RCB is a prognostic marker independent from the type of primary chemotherapeutic regime and significant differences have been described between RCB classes among hormone receptor positive (ER+ and/or PR+, HER2-), HER-2 positive (hormone receptor positive or negative) and triple negative (ER-, PR, HER2-) breast cancer cases [32]. Our results support these conclusions, and moreover, by adding primary endocrine therapy to our calculations, RCB remained an independent prognostic marker.

Considering literature data and our results, $\mathrm{RCB}$ is highly recommended to be included in routine histopathological reports of breast cancers treated with NAT. Although most elements of RCB are routinely part of histopathological reports, the characterization of some others, namely the second largest dimension of tumor size, the cellularity and the proportion of DCIS, require experience in practice. The standardization of reporting these markers are supported by the concise guidance at the RCB calculator website [32].

Corben and co-authors emphasized the role of the presence and size of lymph node metastasis. Those grading systems that include lymph node status (RCB, Sataloff, TR-NR, RDBN) 
show better correlation with long term survival than those including only invasive tumor size and cellularity [5]. In keeping with Corben's results, we found the ypN category as a significant prognostic marker according to OS estimates. The presence of nodal metastasis was associated with poor prognosis regardless of the presence or absence of nodal regression. Corben and coworkers suggested the RDBN grade to be the most optimal regression grading system among the 5 investigated [5]. However, we found no significant differences in DFS or OS between the RDBN groups with Cox regression. This contrast may be due to different factors, like the differences in patients and in cohort sizes (62 vs 746) and the inclusion of primary endocrine therapy in the present analysis.

Concerning the limitations of our study, it has to be mentioned that not all grading systems were assessed in all cases. Several patients had gone through lymphadenectomy prior to NAT and this could influence the prognostic value of a given grading system. Furthermore, the institution where the core needle biopsy was taken differed from the place of surgery in many cases, therefore the comparison of these samples was not always possible. On the other hand, the strengths of our evaluation include a large cohort of patients having primary endocrine treatment or chemotherapy with relatively long follow-up data. Our multicenter study was based on two Hungarian departments with identical cut-up and reporting protocol, following the recommendations of the 3rd Hungarian Consensus Conference on Breast Cancer. Although not all grading systems were evaluated in all cases, even the smallest group included more than 200 patients, and this proved sufficient for statistical analysis.

In our retrospective study involving the grading of response to NAT in 746 patients, we have evaluated and compared the impact of different regression grading systems on DFS and OS. According to our results, the RCB was the best prognostic factor, therefore we would encourage its utilization in routine histopathological reports.

Acknowledgements We gratefully acknowledge the assistance of Mihály Dezső in designing figures.

Authors' Contributions All authors contributed to the study conception and revision. Data collection was performed by Anita Sejben, Renáta Kószó and Zsuzsanna Kahán. Statistical analysis was performed by Anita Sejben and Tamás Zombori. The first draft of the manuscript was written by Anita Sejben and Tamás Zombori and all authors commented on previous versions of the manuscript. All authors read and approved the final manuscript.

Funding Information Open access funding provided by University of Szeged.

Data Availability The datasets generated during and/or analysed during the current study are available from the corresponding author on reasonable request.

Code Availability There are no restrictions on the availability of materials, data and code.

\section{Compliance with Ethical Standards}

This retrospective study was approved by the institutional ethical committee of the Albert Szent-Györgyi Clinical Centre of the University of Szeged.

Conflict of Interest The authors declare that they have no conflict of interest.

Open Access This article is licensed under a Creative Commons Attribution 4.0 International License, which permits use, sharing, adaptation, distribution and reproduction in any medium or format, as long as you give appropriate credit to the original author(s) and the source, provide a link to the Creative Commons licence, and indicate if changes were made. The images or other third party material in this article are included in the article's Creative Commons licence, unless indicated otherwise in a credit line to the material. If material is not included in the article's Creative Commons licence and your intended use is not permitted by statutory regulation or exceeds the permitted use, you will need to obtain permission directly from the copyright holder. To view a copy of this licence, visit http://creativecommons.org/licenses/by/4.0/.

\section{References}

1. Giordano SH (2003) Update on locally advanced breast cancer. Oncologist 8:521-530. https://doi.org/10.1634/theoncologist.8-6-521

2. Rustogi A, Budrukkar A, Dinshaw K, Jalali R (2005) Management of locally advanced breast cancer: evolution and current practice. J Can Res Ther 1:21-30. https://doi.org/10.4103/0973-1482.16086

3. Thompson AM, Moulder-Thompson SL (2012) Neoadjuvant treatment of breast cancer. Ann Oncol 23:231-236. https://doi.org/10. 1093/annonc/mds324

4. Dani M, McDonnell J, Karp S, Jaffe V (2007) Do breast cancer tumours downsize as well as downgrade with neoadjuvant chemotherapy? Breast Cancer Res 9:SP3. https://doi.org/10.1186/bcr1709

5. Corben AD, Abi-Raad R, Popa I, Chy T, Macklin EA, Koerner FC, Taghian AG, Brachtel EF (2013) Pathologic response and longterm follow-up in breast cancer patients treated with neoadjuvant chemotherapy. A comparison between classifications and their practical application. Arch Pathol Lab Med 137:1074-1082. https://doi.org/10.5858/arpa.2012-0290-OA

6. Kaufmann M, von Minckwitz G, Mamounas EP, Cameron D, Carey LA, Cristofanilli M, Denkert C, Eiermann W, Gnant M, Harris JR, Karn T, Liedtke C, Mauri D, Rouzier R, Ruckhaeberle E, Semiglazov V, Symmans WF, Tutt A, Pusztai L (2012) Recommendations from an international consensus conference on the current status and future of neoadjuvant systemic therapy in primary breast cancer. Ann Surg Oncol 19:1508-1516. https:// doi.org/10.1245/s10434-011-2108-2

7. Philipovskiy A, Corral J, Dwivedi KA, Heydarian R, Gaur S (2019) Efficacy of neoadjuvant versus adjuvant chemotherapy in Hispanic/ Latino $(\mathrm{H} / \mathrm{L})$ women with local or locally advanced triple-negative breast cancer (TNBC). In Vivo 33:1227-1234. https://doi.org/10. 21873/invivo. 11594

8. Coates AS, Winer EP, Goldhirsch A, Gelber RD, Gnant M, PiccartGebhart M, Thürlimann B, Senn HJ, Panel Members (2015) Tailoring therapies - improving the management of early breast cancer: St Gallen international expert consensus on the primary therapy of early breast cancer. Ann Oncol 26:1533-1546. https:// doi.org/10.1093/annonc/mdv221

9. Senkus E, Kyriakides S, Ohno S, Penault-Llorca F, Poortmans P, Rutgers E, Zackrisson S, Cardoso F, Guidelines Committee ESMO (2015) Primary breast cancer: ESMO clinical practice Guidelines 
for diagnosis, treatment and follow-up. Ann Oncol 26:8-30. https:// doi.org/10.1093/annonc/mdv298

10. Provenzano E, Bossuyt V, Viale G, Cameron D, Badve S, Denkert C, MacGrogan G, Penault-Llorca F, Boughey J, Curigliano G, Dixon JM, Esserman L, Fastner G, Kuehn T, Peintinger F, von Minckwitz G, White J, Yang W, Symmans WF (2015) Residual disease characterization working Group of the Breast International Group-North American Breast Cancer Group Collaboration. Standardization of pathologic evaluation and reporting of postneoadjuvant specimens in clinical trials of breast cancer: recommendations from an international working group. Mod Pathol 28:1185-1201. https://doi.org/10.1038/modpathol.2015.74

11. Cserni G, Kulka J, Francz M, Járay B, Kálmán E, Kovács I, Krenács T, Udvarhelyi N, Vass L (2016) Pathological diagnosis, work-up and reporting of breast cancer. Recommendations of the 3rd Hungarian consensus conference on breast Cancer. Magy Onkol 60:209-228

12. von Minckwitz G, Untch M, Blohmer JU, Costa SD, Eidtmann H, Fasching PA, Gerber B, Eiermann W, Hilfrich J, Huober J, Jackisch C, Kaufmann M, Konecny GE, Denkert C, Nekljudova V, Mehta K, Loibl S (2012) Definition and impact of pathologic complete response on prognosis after neoadjuvant chemotherapy in various intrinsic breast cancer subtypes. J Clin Oncol 30:1796-1804. https://doi.org/10.1200/JCO.2011.38.8595

13. U.S. Food and Drug Administration (2014) Guidance for Industry: Pathological complete response in neoadjuvant treatment of highrisk early-stage breast cancer: use as an endpoint to support accelerated approval. http://www.fda.gov/downloads/Drugs/ GuidanceComplianceRegulatoryInformation/Guidances/ UCM305501.pdf Accessed 19 Jan 2020

14. Amin MB, Edge S, Greene F, Byrd DR, Brookland RK, Washington MK, Gershenwald JE, Compton CC, Hess KR, Sullivan DC, Jessup JM, Brierly JD, Gaspar LE, Schilsky RL, Balch CM, Winchester DP, Madera M, Asare EA (2017) AJCC Cancer staging manual, 8th edn. Springer, Chicago

15. Sethi D, Sen R, Parshad S, Khetarpal S, Garg M, Sen J (2012) Histopathologic changes following neoadjuvant chemotherapy in various malignancies. Int J Appl Basic Med Res 2:111-116. https://doi.org/10.4103/2229-516X.106353

16. Park CK, Jung WH, Koo JS (2016) Pathologic evaluation of breast cancer after neoadjuvant therapy. J Pathol Transl Med 50:173-180. https://doi.org/10.4132/jptm.2016.02.02

17. Mamounas EP, Anderson SJ, Dignam JJ, Bear HD, Julian TB, Geyer CE Jr, Taghian A, Wickerham DL, Wolmark N (2012) Predictors of locoregional recurrence after neoadjuvant chemotherapy: results from combined analysis of National Surgical Adjuvant Breast and bowel project B-18 and B-27. J Clin Oncol 30:39603966. https://doi.org/10.1200/JCO.2011.40.8369

18. Chevallier B, Chollet P, Merrouche Y, Roche H, Fumoleau P, Kerbrat P, Genot JY, Fargeot P, Olivier JP, Fizames C et al (1995) Lenograstim prevents morbidity from intensive induction chemotherapy in the treatment of inflammatory breast cancer. J Clin Oncol 13:1564-1571. https://doi.org/10.1200/JCO.1995.13.7.1564

19. Sataloff DM, Mason BA, Prestipino AJ, Seinige UL, Lieber CP, Baloch Z (1995) Pathologic response to induction chemotherapy in locally advanced carcinoma of the breast: a determinant of outcome. J Am Coll Surg 180:297-306

20. Ogston KN, Miller ID, Payne S, Hutcheon AW, Sarkar TK, Smith I, Schofield A, Heys SD (2003) A new histological grading system to assess response of breast cancers to primary chemotherapy: prognostic significance and survival. Breast 12:320-327. https://doi.org/ 10.1016/s0960-9776(03)00106-1

21. Denkert C, Schickling O, von Minckwitz G (2006) Preoperative chemotherapy in breast cancer and the development of new predictive markers. Verh Dtsch Ges Pathol 90:114-123

22. Symmans WF, Peintinger F, Hatzis C, Rajan R, Kuerer H, Valero V, Assad L, Poniecka A, Hennessy B, Green M, Buzdar AU, Singletary
SE, Hortobagyi GN, Pusztai L (2007) Measurement of residual breast cancer burden to predict survival after neoadjuvant chemotherapy. J Clin Oncol 28:4414 4422. 10.1200/JCO.2007.10.6823

23. Wells CA, Amendoeira I, Bellocq JP, Bianchi S, Boecker W, Borisch B, Rasmussen B, Callagy GM, Chmielik E, Cordoba A, Cserni G, Decker T, DeGaetano J, Drijkoningen M, Ellis IO, Faverly DR, Foschini MP, Frković-Grazio S, Grabau D, Heikkilä P, Iacovou E, Jacquemier J, Kaya H, Kulka J, Lacerda M, Liepniece-Karele I, Martinez-Penuela J, Quinn CM, Rank F, Regitnig P, Reiner A, Sapino A, Tot T, Van Diest P, Varga Z, Wesseling J, Zolota V, Zozaya-Alvarez E (2013) S2: pathology update. Quality assurance guidelines for pathology. In: European guidelines for quality assurance in breast cancer screening and diagnosis. Fourth edition, Supplements. Perry N, Broeders M, de Wolf C, Törnberg S, Holland R, von Karsa L (eds.). European Commission, Office for Official Publications of the European Union, Luxembourg, pp. 73-120

24. Chollet P, Abrial C, Durando X, Thivat E, Tacca O, MouretReynier MA, Leheurteur M, Kwiatkowski F, Dauplat J, PenaultLlorca F (2008) A new prognostic classification after primary chemotherapy for breast cancer: residual disease in breast and nodes (RDBN). Cancer J 14:128-132. https://doi.org/10.1097/PPO. 0b013e31816bdea2

25. Fowler AM, Mankoff DA, Joe BN (2017) Imaging neoadjuvant therapy response in breast cancer. Radiology 285:358-375. https:// doi.org/10.1148/radiol.2017170180, 285, 358, 375

26. Royal College of Pathologists of Australasia (2012) Invasive breast cancer structured reporting protocol. https://www.rcpa.edu.au/ getattachment/7b70b3e5-5dca-403f-893e-638815f487b1/Protocolinvasive-breast-cancer.aspx. Accessed 22 Nov 2019

27. Lambein K, Van de Vijver K, Faverly D, Colpaert C (2011) Belgian guidelines for laboratory handling and pathology reporting of breast carcinoma after neoadjuvant therapy. Belg J Clin Oncol 5:144-153. https://doi.org/10.1111/j.1365-2559.2006.02419.x

28. Arbeitsgemeinschaft Gynäkologische Onkologie Studiengruppe (2018) Diagnosis and treatment of patients with primary and metastatic breast cancer. https://www.ago-online.de/fileadmin/ downloads/leitlinien/mamma/2018-03/EN/Gesamt PDF Englisch/Updated_Guidelines_2018.pdf.

29. NHS Cancer Screening Programmes jointly with The Royal College of Pathologists (2005) Pathology reporting of breast disease. https:/www.cmcanceralliance.nhs.uk/application/files/3615/ 4815/5660/Guidelines_for_NHSBSP58_January_2005 Reviewed_CNG_June_2010.pdf Accessed 18 Jan 2020

30. Integraal Kankercentrum Nederland (2012) Beoordeling na neoadjuvante chemo- of endocriene therapie. http://www. oncoline.nl/breastcancer Accessed 26 June 2018

31. Lester SC, Bose S, Chen YY, Connolly JL, de Baca ME, Fitzgibbons PL, Hayes DF, Hill KA, Kleer C, O’Malley FP, Page DL, Smith BL, Tan LK, Weaver DL, Winer E, Simpson JF (2012) Protocol for the examination of specimens from patients with invasive carcinoma of the breast. http://www.cap.org/ShowProperty? nodePath=/UCMCon/Contribution\%20Folders/WebContent/pdf/ cp-breast-invasive-16protocol-3300.pdf Accessed 22 Nov 2019

32. Symmans WF, Wei C, Gould R, Yu X, Zhang Y, Liu M, Walls A, Bousamra A, Ramineni M, Sinn B, Hunt K, Buchholz TA, Valero V, Buzdar AU, Yang W, Brewster AM, Moulder S, Pusztai L, Hatzis C, Hortobagyi GN (2017) Long-term prognostic risk after neoadjuvant chemotherapy associated with residual cancer burden and breast cancer subtype. J Clin Oncol 35:1049-1060. https://doi. org/10.1200/JCO.2015.63.1010

Publisher's Note Springer Nature remains neutral with regard to jurisdictional claims in published maps and institutional affiliations. 